\title{
Immunoglobulin G4-Related Disease Masquerading Anaplastic Thyroid Carcinoma
}

\author{
Ji-a Kim, $\mathrm{MD}^{1}$, Min-gyu Jo, $\mathrm{MD}^{1}$, Seok-hyun Kim, $\mathrm{MD}^{1}$, Young Geum Kim, $\mathrm{MD}^{2}$ and Wonjae Cha, MD, $\mathrm{PhD}^{1,3}$ \\ ${ }^{I}$ Department of Otorhinolaryngology-Head and Neck Surgery and Biomedical Research Institute; \\ ${ }^{2}$ Pathology, Pusan National University Hospital, Busan, Korea
}

\begin{abstract}
- ABSTRACT -
Immunoglobulin G4-related disease (IgG4RD) is a chronic inflammatory condition characterized by tissue infiltration with lymphocytes and IgG4-secreting plasma cells, as well as varying degrees of fibrosis. We report a case of a 70-year-old man with a rapid-growing cervical mass for several months. Computed tomography and positron emission tomography showed a huge, ill-defined mass involving left thyroid lobe and encasing the common carotid artery, which was clinically and radiologically suspicious for anaplastic thyroid carcinoma. Ultrasonography-guided core needle biopsy was performed and histopathology examination revealed to be consistent with IgG4RD, and the IgG4/IgG ratio was 0.6. After oral corticosteroid was administered, the mass was dramatically resolved. Because IgG4RD often presents as a single localized and infiltrated mass lesion, it can be confused and misdiagnosed as a malignancy. Thus, clinicians should consider IgG4RD as a differential diagnosis in a rapid-growing neck mass to prevent unnecessary and excessive treatments. (J Clinical Otolaryngol 2018;29:301-306)
\end{abstract}

KEY WORDS : Immunoglobulin G4-related disease · Anaplastic thyroid carcinoma · Inflammatory tumor · Neck mass.

\section{Introduction}

Immunoglobulin G4-related disease (IgG4RD) is a chronic inflammatory condition characterized by tissue infiltration with lymphocytes and IgG4-secreting plasma cells, as well as varying degrees of fibrosis. Although the exact cause of IgG4RD is unknown, it has been reported to have various manifestations. ${ }^{1)}$ The head and neck region is the second most commonly involved site in IgG4RD, and the lacrimal gland, salivary gland, cervical lymph nodes, and nerves have been reported to be involved by IgG4RD, ${ }^{2,3)}$

논문접수일 : 2018년 9월 17일

논문수정일 : 2018년 10월 30일

심사완료일 : 2018년 11월 8일

교신저자 : 차원재, 49241 부산광역시 서구 구덕로 179

부산대학교 의과대학 부산대학교병원 이비인후과학교실

전화 : (051) 240-7336·전송 : (051) 246-8668

E-mail:chawonjae@gmail.com
The differential diagnosis of a soft-tissue neck mass is broad and includes both benign and malignant processes. ${ }^{4}$ Unlike malignancy or other infectious diseases, IgG4RD responds well to corticosteroids with other immunomodulators used as second-line treatment. Therefore, considering IgG4RD in the differential diagnosis is important to prevent a patient from undergoing unnecessary and excessive treatments. ${ }^{5)}$ However, because the disease often presents as a single localized and infiltrated mass lesion, it can make clinicians confused and misdiagnose as a malignancy.

Herein, we report the case of a 70-year-old man presenting with a rapidly growing cervical mass masquerading anaplastic thyroid carcinoma, which was finally revealed as IgG4RD.

\section{Case Report}

A 70-year-old man, with a history of hypertension, 
benign prostatic hypertrophy, and cerebral infarction, complained of a rapidly growing, huge left anterolateral cervical mass for 2 months. At first presentation, the clinical impression was anaplastic thyroid carcinoma with cervical lymph node involvement.

The computed tomography (CT) showed the huge, ill-defined neck mass encasing the left common carotid artery and invading the left thyroid gland and the adjacent cervical structures (Fig. 1A, B, C) The positron emission tomography (PET) revealed a hypermetabolic mass in the left neck (level II to V) and increased fluorodeoxyglucose uptake in the left thyroid gland (Fig. 1D). Laboratory tests were performed at presentation showed an upper-normal range of leukocytosis $(9870 / \mu \mathrm{L})$ with normal percentage of neutrophil (57.6\%), elevated C-reactive protein level $(5.83 \mathrm{mg} / \mathrm{dL})$, and elevated erythrocyte sedimentation rate $(56.0 \mathrm{~mm} / \mathrm{h})$. The serum $\mathrm{IgG} 4$ level was not as- sessed at initial presentation. Ultrasonography-guided core needle biopsy (CNB) was performed for definite pathological confirmation.

Histopathologic examination showed that the lesion had lymphoplasmacytic infiltration and storiform pattern of fibrosis with no evidence of obliterative phlebitis, the $\mathrm{IgG} 4 / \mathrm{IgG}$ positive cell ratio of $60 \%$, and the IgG4 positive cell count of 68 per high power field (HPF) (Fig. 2). Additional serum IgG subclass laboratory test was done after biopsy report. Total serum IgG level was $939 \mathrm{mg} / \mathrm{dL}$, and serum IgG4 level was $84.2 \mathrm{mg} / \mathrm{dL}$.

On the basis of these findings, it was finally diagnosed as IgG4RD. After 2 months of oral corticosteroid treatment, histopathologic examination and $\mathrm{CT}$ were performed to evaluate the treatment response. It showed remarkable decrease in lymphoplasmacytic infiltration and a dramatic reduction in the size of the
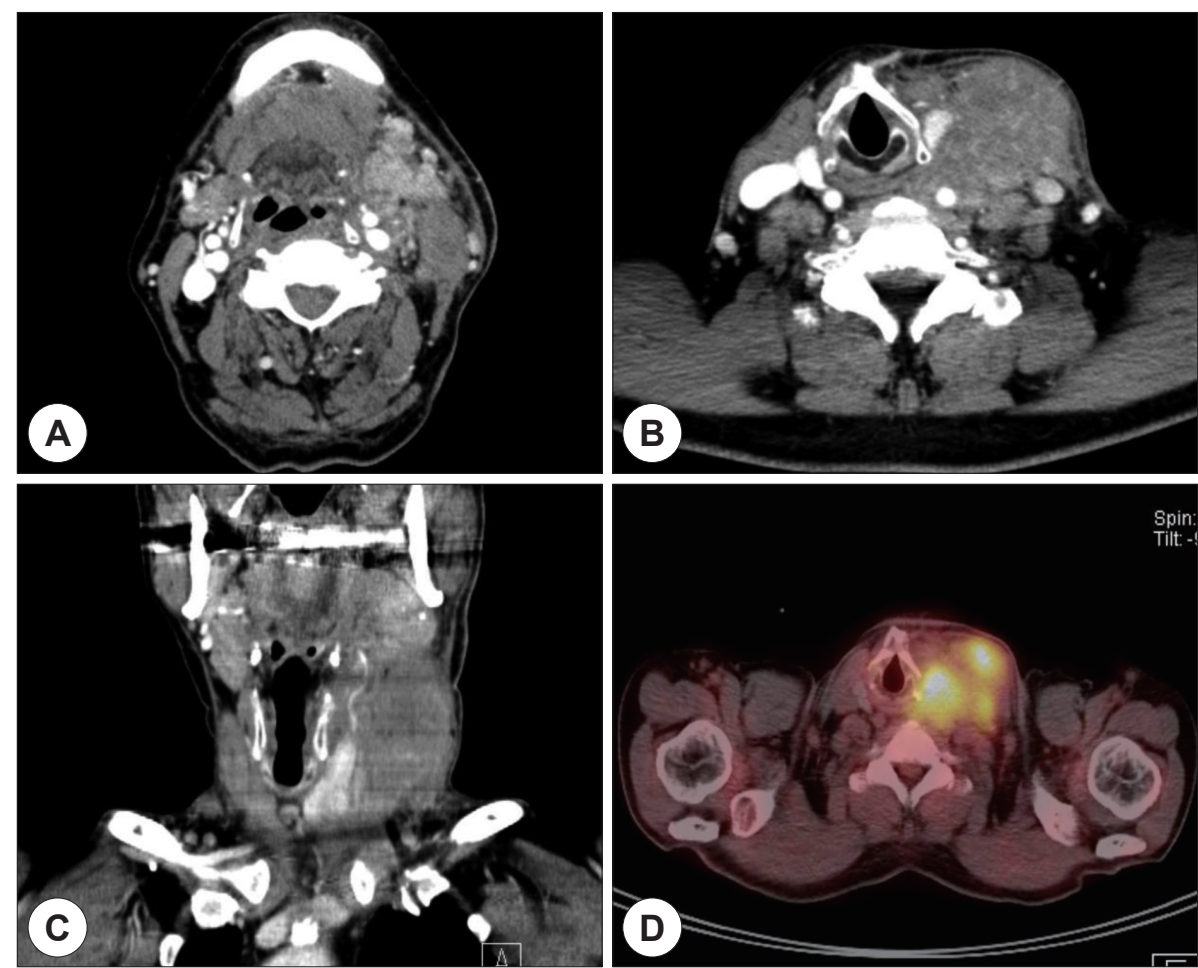

Fig. 1. Computed tomography (CT) and positron emission tomography (PET) images acquired at first visit. A : CT axial view, at the hyoid greater horn level. B : CT axial view, at the thyroid cartilage level. C : CT coronal view. D : PET-CT axial view, at the thyroid cartilage level. Radiologic studies showed ill-defined left neck mass encasing the left common carotid artery and involving the left thyroid gland and the adjacent cervical structures. 

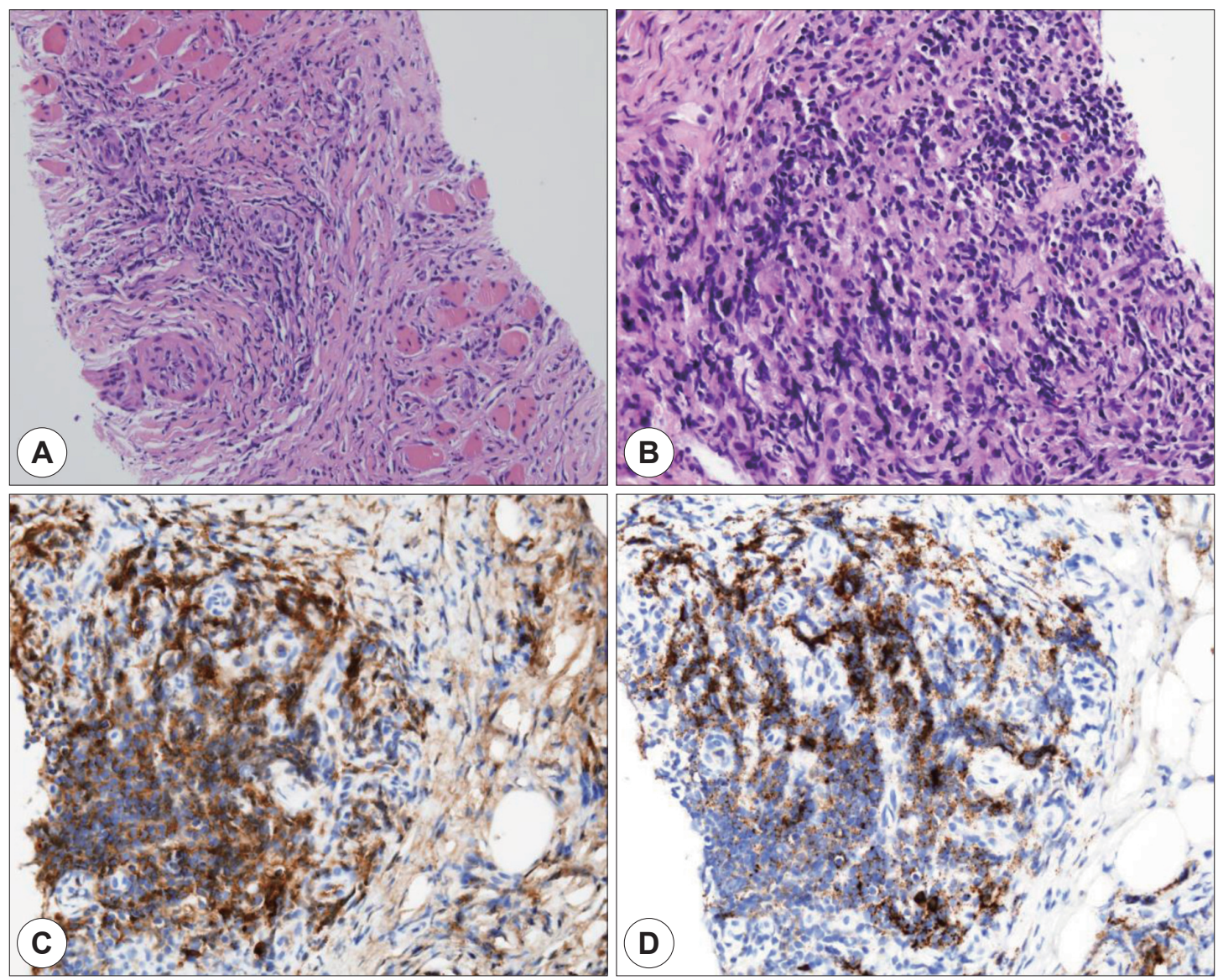

Fig. 2. Histopathologic findings obtained by ultrasonography-guided core needle biopsy. A : Hematoxylin and eosin (H\&E) staining $(100 \times)$, storiform pattern of fibrosis with plasma cells. B : H\&E staining $(400 \times)$, lymphoplasmacytic infiltration. C : Immunostaining of IgG (brown color). D : Immunostaining of IgG4 (brown color); IgG4/lgG ratio was $60 \%$.
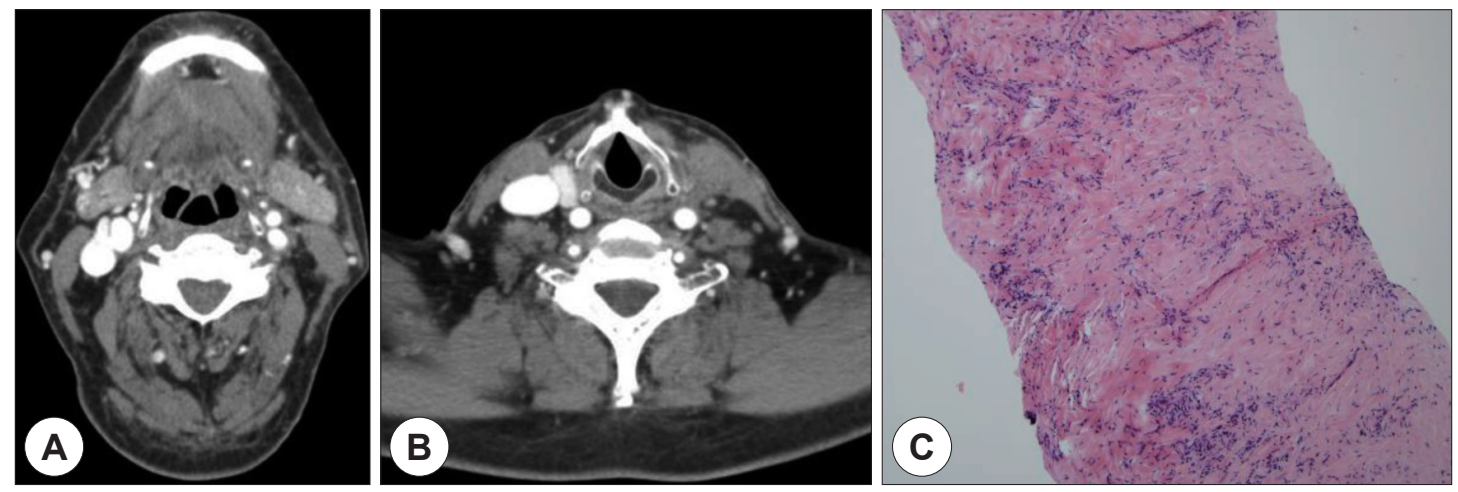

Fig. 3. Computed tomography (CT) images and histopathologic findings after 2 months of oral corticosteroid treatment. A : CT axial view, at the hyoid greater horn level. B : CT axial view, at the thyroid cartilage level. CT axial views showed a dramatic reduction in the size of the left neck mass with no tracheal deviation. $C$ : Histopathologic findings of the left neck mass. Hematoxylin and eosin (H\&E) staining (100 $\times)$ showed remarkable decrease of lymphocyte infiltration. 
mass (Fig. 3). There has been no evidence of recurrence for 6 months.

\section{Discussion}

IgG4RD is a novel clinical entity, first proposed in relation to autoimmune pancreatitis by Japanese investigators in 20016. Since then, this condition has been identified in almost every organ system with many clinical manifestations. The head and neck region is the second most common site of presentation of IgG4RD, which most often presents as a mass lesion. ${ }^{3)}$ According to a systematic review of IgG4RD presentation in the head and neck, the most common site of presentation was the orbit $(\mathrm{n}=384,52.6 \%)$ among the 730 presentations of systemic and head and neck manifestations. ${ }^{3)}$ Relatively, the thyroid gland was a rare involvement site and manifested as Riedel's thyroiditis $(\mathrm{n}=31,4.2 \%))^{3)}$ Thyroid involvement has been postulated as a variant of thyroiditis. For example, Riedel's thyroiditis has been immunohistochemically proven to be a part of the IgG4RD spectrum, ${ }^{7)}$ and fibrosing variant of Hashimoto's thyroiditis is also a part of the IgG4RD spectrum. ${ }^{6}$ Moreover, several case reports have also documented thyroid papillary carcinoma with IgG4+ plasma cells and fibrosis. ${ }^{8}$

Laboratory or radiologic tests to diagnose IgG4RD accurately are currently unavailable. Serum IgG4 elevation showed poor specificity $(60 \%)$ and low positive predictive value (34\%) because it could increase in non-IgG4 related condition-malignancies or immune-mediated conditions, such as Sjogren syndrome, Mikulicz's disease, granulomatosis with polyangiitis, Churg-Strauss syndrome, and sarcoidosis. ${ }^{9)}$ Moreover, imaging studies are not critical for a diagnosis of IgG4RD. ${ }^{10)}$ Thus, confirmatory biopsy is mandatory to exclude various conditions mentioned above and accurately diagnose IgG4RD. Especially in soft tissue mass with a suspicion of autoimmune disease, CNB was preferred modality because it can obtain tissue specimen with more preserved architecture. ${ }^{11,12)}$ Although histopathologic examination alone is not a comprehen- sive clinical criterion, it is a gold standard for the diagnosis of IgG4RD. ${ }^{13)}$

The team of the Research Program for Intractable Disease, Ministry of Health, Labor and Welfare in Japan has proposed the criteria for the diagnosis of IgG4RD in 2011. ${ }^{14,15)}$ They called it as "comprehensive diagnostic criteria" to cover various organ involving cases, not organ specific. It contains three major criteria of clinical, laboratory and histopathologic features : (1) clinical features like characteristic diffuse/ localized swelling or masses in single or multiple organs, (2) laboratory data with elevated serum IgG4 concentrations ( $\geq 135 \mathrm{mg} / \mathrm{dL}$ ), (3) histopathologic features like marked lymphoplasmacytic infiltration and fibrosis, infiltration of IgG4 positive plasma cells (the ratio of IgG4/IgG-positive cells $>40 \%$ and IgG4positive cells/HPF >10). According to the criteria, it can be categorized as "definite IgG4RD" (with all the criteria satisfied), "probable IgG4RD" (with the clinical and histopathologic satisfied), and "possible IgG4RD" (with the clinical and laboratory criteria satisfied). However, it is important to differentiate from other similar diseases (e.g. malignant tumors, Sjogren's syndrome, Churg-Strauss syndrome and Castleman's disease).

Deshpande et al. suggested the international consensus statement on the pathology of IgG4RD. ${ }^{17)}$ They suggested three criteria for conclusive diagnosis on the basis of characteristic quantitative and qualitative histopathologic findings in biopsy specimens obtained from affected tissues. According to the statement, IgG4/ IgG-positive cell ratio of $>40 \%$ is mandatory for the diagnosis of IgG4RD. Three characteristic histopathologic features for IgG4RD were suggested : (1) a dense lymphoplasmacytic infiltrate, (2) storiform pattern of fibrosis, and (3) obliterative phlebitis. And the tissuespecific threshold of the number of IgG4-positive cells/ HPF were established by expert consensus. ${ }^{13,16)}$ According to the algorithm, IgG4RD was categorized as the two groups : "highly suggestive" of IgG4RD (with two or more major histopathologic features) and "probable" IgG4RD (with just one histopathologic feature).

In this case, the patient complained of a rapidly grow- 
ing left cervical mass for several months. CT and PET revealed the huge, ill-defined mass encasing the common carotid artery and invading the left thyroid, as well as multiple metastatic lymph nodes and salivary glands. Although there are many reports about IgG4RD with thyroiditis, ${ }^{4,17)}$ the patients had no history for hypoor hyper-thyroidism, and diffuse thyroid enlargement. Laboratory data showed elevated ESR and CRP level, normal range of white blood cell count, and serum IgG4 of $84.2 \mathrm{mg} / \mathrm{dL}$ with total serum $\mathrm{IgG}$ of $939 \mathrm{mg} / \mathrm{dL}$. Histopathologic examination revealed lymphoplasmacytic infiltration and storiform pattern of fibrosis with no evidence of obliterative phlebitis. And, $\mathrm{IgG} 4+/ \mathrm{IgG}+$ cell ratio was $60 \%$ in biopsy and the number of $\mathrm{IgG} 4$ positive plasma cell count/HPF was 68 . These findings satisfied the clinical and histopathological features of Japan's criteria, thus it could be diagnosed as "probable" IgG4RD. ${ }^{14,15)}$ Also, according to the international consensus, two characteristic findings met with the histopathologic criteria, and the $\mathrm{IgG} 4+/ \mathrm{IgG}$ ratio was greater than $40 \%(60 \%)$. The number of IgG4posititve cell count/HPF was not sufficient to diagnose highly suggestive of IgG4RD. However, the specific threshold of thyroid tissue is not established. Considering the cut-off value for the biopsies of various organs is $>10$ or $>20$, the cell number of 68 is not low in this case. Comprehensively, it could be diagnosed as probable IgG4RD according to the international criteria.

On the basis of the above findings, it was clinically diagnosed as IgG4RD and we decided the steroid treatment for the patient. After 2 months of an oral corticosteroid treatment, histopathologic examination and CT was done to evaluate the treatment response. It showed remarkable decrease in lymphoplasmacytic infiltration and a dramatic reduction in the size of the mass. Even if he had rare clinical feature (thyroid invaded unilateral cervical mass), histopathologic findings are suitable for IgG4RD, and it showed good response to corticosteroid treatment. Thus, confirmatory biopsy is mandatory to exclude various conditions and accurately diagnose IgG4RD.
The differential diagnosis of a cervical mass is broad and includes both benign and malignant processes. The treatments for cervical mass are in the broad spectrum- medical, interventional, surgical, or sometimes observational strategies. Therefore, the failure of accurate diagnosis can lead unnecessary and invasive treatment or disease progression because IgG4RD is an autoimmune disease and responds to corticosteroids. ${ }^{4,17)}$ Therefore, clinicians should consider IgG4RD as a differential diagnosis for mass lesions mimicking head and neck malignancies.

This work was supported by clinical research grant from Pusan National University Hospital in 2018.

\section{REFERENCES}

1) Stone JH, Khosroshahi A, Deshpande V, Chan John KC, Heathcote JG, Aalberse R, et al. Recommendations for the nomenclature of IgG4-related disease and its individual organ system manifestations. Arthritis Rheum 2012;64(10): 3061-7.

2) Park HG, Kim KM. IgG4-related inflammatory pseudotumor of the renal pelvis involving renal parenchyma, mimicking malignancy. Diagn Pathol 2016;11(1):12.

3) Mulholland GB, Jeffery CC, Satija P, Cote DW. Immunoglobulin G4-related diseases in the head and neck: a systematic review. J Otolaryngol Head Neck Surg 2015;44:24.

4) McKinnon T, Randazzo WT, Kim BD, Biddinger P, Forseen S. IgG4-Related Disease Presenting as a Solitary Neck Mass. J Radiol Case Rep 2015;9(2):1-8.

5) Umehara H, Okazaki K, Masaki Y, Kawano M, Yamamoto $\mathrm{M}$, Saeki T, et al. A novel clinical entity, IgG4-related disease (IgG4RD): general concept and details. Mod Rheumatol 2012;22(1):1-14.

6) Hamano H, Kawa S, Horiuchi A, Unno H, Furuy N, Akamatsu T, et al. High serum IgG4 concentrations in patients with sclerosing pancreatitis. N Engl J Med 2001;344(10): 732-8.

7) Dahlgren M, Khosroshahi A, Nielsen GP, Deshpande V, Stone JH. Riedel's thyroiditis and multifocal fibrosclerosis are part of the IgG4-related systemic disease spectrum. Arthritis Care Res (Hoboken) 2010;62(9):1312-8.

8) Ito M, Naruke Y, Mihara Y, So K, Miyashita T, Origuchi T, et al. Thyroid papillary carcinoma with solid sclerosing change in IgG4-related sclerosing disease. Pathol Int 2011;61(10): 589-92.

9) Carruthers MN, Khosroshahi A, Augustin T, Deshpande V, Stone JH. The diagnostic utility of serum IgG4 concentrations in IgG4-related disease. Ann Rheum Dis 2015;74(1): 14-8.

10) Umeno H, Chitose $S$, Sato K, Ueda Y, Nakashima T. Long- 
term postoperative vocal function after thyroplasty type I and fat injection laryngoplasty. Ann Otol Rhinol Laryngol 2012;121(3):185-91.

11) Kasraeian S, Allison DC, Ahlmann ER, Fedenko AN, Menendez LR. A comparison of fine-needle aspiration, core biopsy, and surgical biopsy in the diagnosis of extremity soft tissue masses. Clin Orthop Relat Res 2010;468(11):29923002.

12) Runge TM, Hart PA, Sasatomi E, Baron TH. Diagnosis of autoimmune pancreatitis using new, flexible EUS core biopsy needles: report of 2 cases. Gastrointest Endosc 2017; 85(6):1311-2.

13) Deshpande V, Khosroshahi A. Diagnostic guidelines for IgG4-related disease with a focus on histopathological criteria. Diagn Histopathol 2013;19(4):119-27.
14) Okazaki K, Umehara H. Are classification criteria for IgG4RD now possible? The concept of IgG4-related disease and proposal of comprehensive diagnostic criteria in Japan. Int J Rheumatol 2012;2012:357071.

15) Umehara H, Okazaki K, Masaki Y, Kawano M, Yamamoto $\mathrm{M}$, Saeki T, et al. Comprehensive diagnostic criteria for IgG4-related disease (IgG4-RD), 2011. Mod Rheumatol 2012; 22(1):21-30.

16) Deshpande V, Zen Y, Chan JK, Yi EE, Sato Y, Yoshino T, et al. Consensus statement on the pathology of IgG4-related disease. Mod Pathol 2012;25(9):1181-92.

17) Segawa Y, Yasumatsu R, Shiratsuchi H, Tamae A, Noda T, Yamamoto H, et al. Inflammatory pseudotumor in head and neck. Auris Nasus Larynx 2014;41(3):321-4. 